\title{
MULTIPLE CRITERIA LAND USE ANALYSIS
}

Jacques Antoine

Food and Agriculture Organization (FAO)

Rome, Italy

Gïnther Fischer

Marek Makowski

International Institute for Applied Systems Analysis

Laxenburg. Austria

RR $-98-5$

March 1998

Reprinted from Applied Mathematics and Computation, Volume 83. pp. 195-215 (1997).

International Institute for Applied Systems Analysis, Laxenburg, Austria Tel: +432236 807 Fax: +43223673148 E-mail: publications@iiasa.ac.at 
Research Reports, which record research conducted at IIASA, are independently reviewed before publication. Views or opinions expressed herein do not necessarily represent those of the Institute, its National Member Organizations, or other organizations supporting the work.

Reprinted with permission from Applied Mathematics and Computation, Volume 83, Pp. 195-215 (1997).

Copyright (c) Elsevier Science Inc., 1997.

All rights reserved. No part of this publication may be reproduced or transmitted in any form or by any means, electronic or mechanical, including photocopy, recording, or any information storage or retrieval system, without permission in writing from the coprright holder. 
NORTH·HOLLAND

\title{
Multiple Criteria Land Use Analysis
}

\author{
Jacques Antoine \\ Land and Water Development Division, AGL B705 \\ Food and Agriculture Organization (FAO) \\ Viale delle Terme di Caracalla \\ I-00100 Rome, Italy
}

Günther Fischer

Land Use Change Project

International Institute for Applied Systems Analysis (IIASA)

Schlossplatz 1, A-2361 Laxenburg, Austria

and

Marek Makowski

Methodology of Decision Analysis

International Institute for Applied Systems Analysis (IIASA)

Schlossplatz 1, A-2361 Laxenburg, Austria

\begin{abstract}
Since the early 1980s, the Food and Agriculture Organization of the United Nations (FAO) and the International Institute for Applied Systems Analysis (IIASA) have been collaborating on expanding FAO's Agro-Ecological Zones (AEZ) methodology of land resources appraisal by incorporating decision support tools for optimizing the use of land resources. Initially, these tools consisted of the application of linear optimization techniques for analyzing land-use scenarios with regard to single objective functions, such as maximizing argicultural production or minimizing the cost of production under specific physical environmental and socio-economic conditions and constraints. Often, the specification of a single objective function does not adequately reflect the preferences of decision-makers, which are of a multiobjective nature in many practical problems dealing with resources. Multicriteria optimization approaches address problem definitions and solutions in a more realistic way and have recently been applied by FAO and IIASA in a land resources appraisal study in Kenya. In this study, optimization techniques coupled with multicriteria decision analysis (MCDA) techniques, using the Aspiration-Reservation Based Decision Sup-
\end{abstract}


port (ARBDS) approach, have been used to analyze various land use scenarios, considering simultaneously several objectives such as maximizing revenues from crop and livestock production, maximizing district self-reliance in agricultural production, minimizing costs of production and environmental damages from erosion. The main users of the new tool being developed, which combines AEZ and MCDA, are expected to be natural resources analysts and managers, land-use planners, ecologists, environmentalists, economists at national and regional levels, and agricultural extensionists at the local scale. (C) Elsevier Science Inc., 1997

\section{INTRODUCTION}

In most developing countries, the socio-economic needs of rapidly increasing populations are the main driving force in the allocation of land resources to various kinds of uses, with food production as the primary land use. In sub-Saharan Africa, in particular, the population may increase at the rate of 25 million people a year until it reaches 2 billion by the year 2050. This rate of increase will double food requirements in many countries [1]. Heavy population pressure and the related increased competition by different types of land users have emphasized the need for more effective land-use planning and policies. Rational and sustainable land use is an issue of great concern to governments and land users interested in preserving the land resources for the benefit of present and future populations.

Policy makers and land users face two basic challenges: the need to reverse trends of land degradation in already cultivated areas by improving conditions and re-establishing their level of fertility; and to prevent the degradation of land resources in new development areas through appropriate and just allocation and use of these resources to maintain productivity and minimize soil erosion. In both cases, an integrated approach to planning and management of land resources is a key factor in a solution which will ensure that land is allocated to uses providing the greatest sustainable benefit. This principle is anchored in Chapter 10 of UNCED Agenda 21.

As Task Manager for Chapter 10, FAO promotes the integrated planning and management of land resources in cooperation with regional institutions and individual countries as well as land users. Land use decisions should be based on comprehensive and quantified assessments of potentials and development possibilities of the land resources, taking into account the biophysical, environmental, and socio-economic factors, as well as the space and time dimensions of sustained land use. Reaching a consensus on land use should be a main objective in the conceptualization of decision support systems (DDS) for sustainable land use. Feasible 'real world' solutions are compromise solutions, resulting from a tradeoff between various conflicting objec- 
tives, thus not maximizing single objectives, but finding an efficient and acceptable balance between the requirements of the stakeholders in the land and resources availability. Different kinds of objectives may need to be included, expressing not only economic values of land products, but also addressing goals which cannot always be expressed in monetary terms such as biodiversity, people's preferences, equity, or minimizing risk and uncertainty. Decision making in land use also involves the consideration of a number of goals which cannot be aggregated into a single criterion to be used as a performance measure for ranking alternatives. Usually, models may have to be run a number of times in order to identify a 'best', or even acceptable, solution. the elements of a solution are not fixed valued but are variable within certain ranges determined by resources availability and socio-economic realities. Many options need to be examined to generate the information and knowledge required for these decisions and to quantify and display the tradeoffs between conflicting objectives.

This entails the use of multicriteria optimization techniques; it also requires the interaction of the various stakeholders in the elaboration of decision support systems in order to ensure the relevance and applicability of the systems and also to facilitate their dissemination, acceptance and use. Brinkman [2] has indicated a three-step approach to the conceptualization of DSS for land use as follows.

(1) Identification of the degree to which the objective functicns of the different actors in the land use allocation process overlap and the ways in which they contrast or may give rise to conflict;

(2) Land use optimization on the basis of the various objective functions of the different actors and analysis of the extent to which the different optimization runs lead to similar land use patterns for the area;

(3) Development and application of interactive methods to maximize the extent of consensus in the adopted land use pattern.

The information produced in this process can then form a common basis and tool for arriving at a negotiated solution for any remaining differences.

MULTIPLE CRITERIA DECISION ANALYSIS FOR INTEGRATED LAND RESOURCES PLANNING AND MANAGEMENT IN THE FAO. ${ }^{1}$

Concurrently with the rapid development of information technology in the last decade, FAO, with the collaboration of the International Institute

\footnotetext{
${ }^{1}$ This paper is a revised version of the paper [3] presented at the First International Conference on Multiple Objective Decision Support Systems for Land, Water and Environment Management: Concepts, Approaches and Applications, held 23-28 July 1995, in Honolulu, Hawaii.
} 
for Applied Systems Analysis ((IIASA), has upgraded its Agro-Ecological Zoning (AEZ) methodology [4] for land resources appraisal which implements the land evaluation approach of FAO's framework for Land Evaluation [5] with DSS tools, including Geographic Information System (GIS) and Linear programming [6].

Linear programming techniques have been used in applying singlecriterion optimization models to sets of AEZ/GIS outputs in order to examine alternative regional or district level land use patterns. Such models suggest feasible land use allocation patterns that best satisfy specified single development objectives, e.g., target food production levels, population supporting capacities or rural employment levels.

The traditional methods used to deal with de facto multiple criteria land use problems are based on the idea of converting a multicriteria problem into a single-criterion one by summing up weighted criteria. This approach has a number of drawbacks, as discussed in detail [7, 8]. Here only the two main arguments are summarized. First, such an approach does not allow for a user-controlled examination of interesting (for him/her) Pareto-optimal solutions. ${ }^{2}$ Second, using weights can produce counter-intuitive results, as one can find examples in which, for certain regions of the efficient frontier, increasing the weight for a critcrion results in worsening of the corresponding criterion value instead of the expected improvement.

Currently, the FAO AEZ/GIS package is being complemented with recent DSS tools devcloped at IIASA $[7,9]$ to deal with multiple criteria decision analysis (MCDA) problems. There are a number of different approaches to multiple criteria decision analysis (see [10] for a review). MCDA techniques are increasingly applied in different areas in agriculture: for instance, food security [11], livestock feed formulation [12], forest management [13], environmental management [14], water resources systems analysis [15], regional water quality management [16]. One of the most successful MCDA methods is the aspiration-led decision support (see [17] for a justification, [18] and [19] for a review). An extension of this method, called Aspiration-Reservation Based Decision Support (further on referred to as ARBDS), has been applied to the case study reported in this paper.

\section{THE ARBDS METHOD}

From the user's point of view, the critical step of MCDA is generating a part of the Pareto-optimal solution set. Generating the entire Pareto set is

\footnotetext{
${ }^{2}$ Efficient, or Pareto-optimal, solutions are those for which an improvement in the value of one criterion cannot be attained without worsening the value of at least one other criterion.
} 
practically impossible. Therefore, most MCDA methods facilitate generation of Pareto-solutions having certain properties. The kinds and combinations of properties are different for every method. The ARBDS uses the most natural way for linking the properties of the Pareto-optimal solutions with the preferences of the decision-maker expressed by aspiration and reservation levels set interactively by the user for each criterion. The ARBDS method provides tools for analyzing Pareto-optimal solutions and generating another set of Pareto-optimal solutions based on these results. Since aspirations are usually not attainable, the decision maker (DM) uses an interactive tool in order to adjust both aspiration and reservation levels until he/she finds a solution which best meets his/her expectations.

The ARBDS method, which has been implemented in the following example, is based on the concept of satisficing behavior (also called bounded rationality), in which the decision maker attempts first to improve the criterion which shows the worst performance [20,21]. This method has a number of noteworthy advantages over other MCDA methods, as discussed in detail along with a more formal presentation of the ARBDS technique in $[7,22]$.

Here we summarize the ARBDS method as a two-stage approach (a more detailed discussion can be bound in [23]).

- First, a core model is specified and generated. The core model contains only a set of constraints that correspond to logical and physical relations between the variables used in the model. The list of variables in the core model should also include variables that represent potential criteria (goals, performance indices). In the preparatory stage, a DM selects out of those variables a set of criteria that will be used for the analysis of the model and specifies for each criterion its type. In addition to commonly used minimized or maximized criteria, one can also use a goal type of criterion (which minimizes a deviation from a given value). There are also techniques that allow for representation of more complicated forms of criteria (like following a trajectory, minimization of a distance, etc.). After the selection of a set of criteria, the DSS performs automatically a series of optimizations in order to compute the Utopia point and an approximation of the Nadir point. ${ }^{3}$ The preparatory stage is finished with computation of the so-called compromise solution which corresponds to a problem for

\footnotetext{
${ }^{3}$ Utopia and Nadir points (in the space of criteria) are vectors composed of best and worst values of the criteria in the efficient set.
} 
which the aspiration and reservation levels are (automatically) set to the Utopia and an approximation ${ }^{4}$ of the Nadir points, respectively.

Second, during an interactive procedure, a DM specifies goals and preferences, including values of criteria that he/she wants to achieve and to avoid. The vectors composed of those values are called aspiration and reservation levels, respectively. These are used to define component achievement functions which are used for selection of a Pareto-optimal solution. This is achieved by generation of additional constraints and variables, which are added by the DSS to the core model, thus forming an optimization problem whose solution results in a Pareto solution that is nearest (in the sense of a measure defined by the aspiration and reservation levels) to the specified aspiration levels (or uniformly better than these levels, if they are attainable).

The structure of a DSS that provides the above outlined functions is illustrated in Figure 1. The DSS is composed of a number of modular and

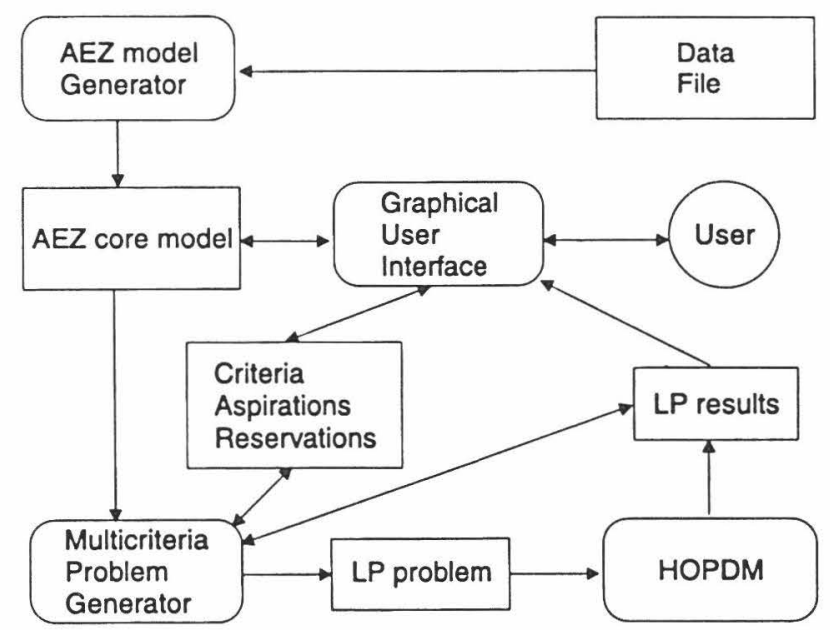

FIG. 1. The structure of a decision support system for the sustainable agricultural development planning.

\footnotetext{
${ }^{4}$ It can be shown (e.g., see [24]) that computation of a Nadir point for problems with more than two criteria may be very difficult. In our approach, the nadir point plays a minor informative role (it only bounds values of corresponding reservation levels). Therefore, there is no justification for spending resources in order to get its better approximation. hence, we assume as an approximation of Nadir the worst value (obtained during the analysis) of a corresponding criterion.
} 
portable software tools that are characterized below with a brief description of their functions.

- A Graphical User Interface (GUI), which handles all the interaction with the user. GUI hides the differences between modules of the DSS from the user by providing a uniform way of interaction with all the components of the DSS.

- A problem-specific model generator for generating the core model which represents in the terms of mathematical programming the model for Sustainable Agricultural Development Planning. It is important to stress that the core model includes only physical and logical relations and not the preferential structure of the DM. A more detailed discussion on core model specification is provided in [7]. In the application discussed in this paper, we have used a core model derived from the linear programming model developed by the authors for a land use case study of Kenya. A detailed mathematical description is provided in [28].

- Interactive definitions of Aspirations, Reservations, and for changing the status of Criteria is done with the SAP-tool (described in [23]) which also supports optional specification of user preferences in terms of fuzzy sets. SAP also provides the user with other means of control over the problem analysis by allowing changing the criteria status, selection of displayed solutions, etc. However, the SAP provides more functions than can be outlined in Figure 1.

- The multicriteria problem generator is implemented with LP-Multi (see [7] for details), a modular tool for handling multiple criteria problems using the methodology outlined above. The resulting Linear Programming (LP) problem is based on the core model and the aspiration and reservation levels which represent the preference structure of a DM.

- HOPDM - a modular LP solver based on the interior point method (see [25] for details). The solver does not require any interaction with the user.

- A data interchange tool LP-DIT described in [9]. This tool provides an easy and efficient way for the definition and modification of LP and MIP problems, as well as the interchange of data between a problem generator, a solver, and software modules which serve for problem modification and solution analysis. LP-DIT is used for the definitions of the core model and the LP problems (the latter defined for each multicriterion problem), as well as for the optimization results.

We concentrate our discussion on presenting in more detail the interactive stage of the ARBDS outlined above. The interaction is handled by the SAP tool and can be summarized in the form of the following steps. 
Step 1. The DM specifies new aspiration and reservation levels for all criteria. For each stabilized criterion (if any), the DM specifies a corresponding target (desired) value and aspiration and reservation levels for a deviation from the specified target value. Optionally, the DM can specify for each criterion his preferences in terms of fuzzy sets.

Step 2. The DM can change the status of each criterion. The default status (originally defined in the preparatory stage) can be changed to stabilized, inactive, or disregarded. A stabilized criterion is used when-instead of minimization or maximization-a user wants to obtain a solution with a criterion value closest to a specified target value. Inactive criteria only enter via the third term in the evaluation of the achievement scalarizing function (see (1)), whereas, disregarded criteria do not enter this evaluation at all.

Step 3. The DM can analyze criteria values of the solutions computed so far (together with values of aspiration and reservation levels used for each solution).

Step 4. The DM may want to store a currently analyzed solution of the underlying LP or MIP problem for a more detailed analysis (which is typically problem specific).

Step 5. The DM can freely switch between the actions summarized above until he/she decides that his/her preferences are properly represented for the next optimization. Once the optimization is selected, the DSS takes over the control of the program flow. The DSS generates a single-criterion optimization problem whose solution is a Pareto-efficient solution which corresponds to the current preference structure of the DM (see below for details) and executes an appropriate solver which computes such a solution. The DM regains the control of the program when the solution of the last specified problem is ready and added to the previously obtained solutions.

The steps described above are repeated in order to explore various Pareto-efficient solutions until a satisfactory solution is found or until the user decides to discontinue the analysis. In either case, the analysis can be continued from the last obtained solution at a later time.

All multicriteria optimization methods assume that a multiobjective problem is converted into an auxiliary parametric single-objective problem whose solution provides a Pareto-optimal point. The methodological background of the conversion is usually hidden from the user. However, here we present its outline for those readers who are interested in the underlying methodology.

Different methods apply different conversions but all commonly known methods can be interpreted (see [7]) in the terms of an achievement scalarizing function. This concept, which was introduced by Wierzbicki (see, 
e.g., $[21,26])$ for the mathematical foundations, interpretations and applications), is very useful for comparing different approaches to multicriteria optimization (see [7] for a comparison).

The following form of the achievement scalarizing function is implemented in the DSS reported here.

$$
S(q, \bar{q}, \underline{q})=\min _{i \in I} u_{i}\left(q_{i}, \bar{q}_{i}, \underline{q}_{i}\right)+\epsilon \sum_{i \in I} u_{i}\left(q_{i}, \bar{q}_{i}, \underline{q}_{i}\right)+\epsilon \sum_{i \in \bar{I}} s_{i} q_{i}
$$

where $\bar{q}_{i}$ and $q_{i}$ are aspiration and reservation levels for the $i$-th criterion, $I$ and $\bar{I}$ are sets of indices of active and inactive criteria, respectively, and the scaling coefficients $s_{i}$ are defined by

$$
s_{i}=\frac{\operatorname{sign}\left(q_{i}^{U}-q_{i}^{N}\right)}{\max \left(1,\left|q_{i}^{U}-q_{i}^{N}\right|\right)}
$$

where $\operatorname{sign}(x)$ is a function that returns 1 for nonnegative numbers and -1 otherwise.

Component achievement functions $u_{i}(\cdot)$ are strictly monotone (decreasing for minimized and increasing for maximized criteria, respectively) functions of the objective vector component $q_{i}$ with values

$$
u_{i}\left(q_{i}^{U}, \cdot\right)=1+\bar{\beta}, u_{i}\left(\bar{q}_{i}, \cdot\right)=1, u_{i}\left(\underline{q}_{i}, \cdot\right)=0, u_{i}\left(q_{i}^{N}, \cdot\right)=-\bar{\eta}
$$

where $q_{i}^{U}$ and $q_{i}^{N}$ are utopia and approximation of nadir values, respectively; $\bar{\beta}$ and $\bar{\eta}$ are given positive constants, typically equal to 0.1 and 10 , respectively.

In order to allow for either specification of only aspiration and reservations levels or for additional specification of preferences (for the criteria values between aspiration and reservation levels) in terms of fuzzy sets, the SAP supports specification of the component achievement functions in a more general form than discussed in [26]. Namely, the piecewise linear functions $u_{i}$ are defined by segments $u_{j i}$

$$
u_{j i}=\alpha_{j i} q_{i}+\beta_{j i}, q_{j i} \leqslant q_{i} \leqslant q_{j+1, i} \quad j=1, \ldots, p_{i}
$$

where $p_{i}$ is a number of segments that define $u_{j i}$. The coefficients defining the segments are defined indirectly by the user, who specifies aspiration and reservation levels as well as (optionally) additional points between those levels (see [7] for details). 


\section{MAKING LAND USE CHOICES IN KENYA DISTRICTS}

The following is an example of the application of the ARBDS method in a district land use case study in Kenya. The basis of this application is a set of GIS-based AEZ land resource inventories of individual districts in Kenya (see [27]). The AEZ land resource inventories combine digitized map overlays that relate to climatic conditions, soil inventory, administrative units, and selected properties of present land use, i.e., cash crop zones, forest areas, irrigation schemes, Tsetse infestation, and game parks. The digitized data were converted to a grid cell or raster database. Each grid cell represents one square kilometer (100 ha). AEZ computer programs are applied to the district land inventories to analyze land suitability and land productivity including cropping patterns, linkage to livestock and forestry production systems and soil erosion considerations. In this way, a land productivity database is generated which contains quantified information on the productivity of all feasible land utilization types for each agro-ecological cell in the districts. It must be mentioned that the preparation of such a resource database is a costly and nontrivial undertaking. In the case study of Kenya, this was achieved thanks to the commitment of FAO and the active collaboration of the Kenyan government and research institutions. The land productivity assessment involves 64 types of food and cash crops, pastures, 31 fuelwood species, and 10 livestock systems. These are grouped into 36 production commodities, including 26 crop and 10 livestock production commodities. This database provides the input to the ARBDS optimization model.

\section{THE MODEL}

Bungoma district in Western province of Kenya is used in this illustrative example, where the authors have assumed the role of the 'decisionmaker.' The district is situated on the slopes and foothills of Mt. Elgon bordering Uganda (district code 801 on Figure 2). The district enjoys good agro-ecological conditions. Presently, grown cereal crops include maize, wheat, barley, and finger millet. The land productivity assessment shows a total arable land potential of about 200,000 ha representing over 60 percent of the entire district. About one third of this area is of only marginal quality. There is good potential for cereals, beans, and potatoes. In addition, cash crops such as coffee, tea, cotton, pyrethrum, and sugar cane can be cultivated.

In the 1989 census, the recorded population in the Bungoma district amounted to 679,000 people, of which some 525,000 lived in rural areas. The 


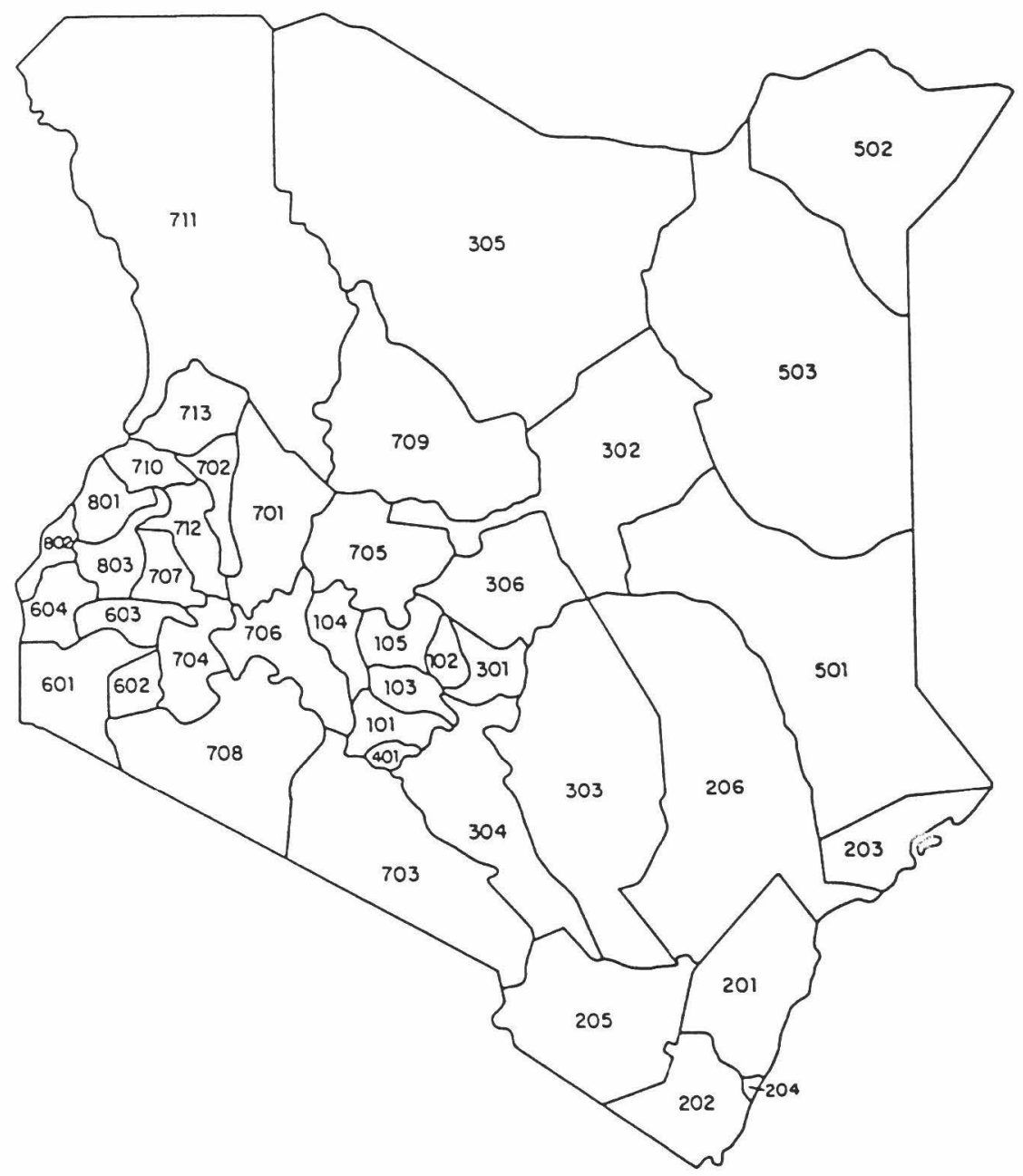

FIG. 2. District map of Kenya.

population in Bungoma is projected to increase to 920,000 in the year 2000, and to some $1,150,000$ in the year 2010. In the past, the growing population density has led to increased fragmentation of holdings. Despite generally favorable conditions, the district is facing increased pressure on its resource base and as a result, enhanced intensification of agricultural production will be required to secure future food supplies and adequate incomes.

The core model accepts user specifiable scenario parameters from a control file, reads crop, grassland, and fuelwood production potentials by 
agro-ecological cells from the land productivity database, reads livestock system related data derived from herd structure models, and determines simultaneously land use by agro-ecological cells as well as supported levels of different livestock systems, feed supplies, and utilization by livestock zone and season (a more detailed discussion is given in [28]). The model provides a framework for specifying different types of objectives and kinds of constraints.

The main issue here is to analyze potential population supporting capacity of the district under various land use scenarios, considering simultaneously several objectives such as maximizing revenues from crop and livestock production, maximizing food output, maximizing district self-reliance in agricultural production, and minimizing environmental damages from erosion. Population supporting capacity, as defined here, relates the maximum potential of soil and climatic resources to produce food energy and protein, at a given level of technology. An intermediate level of input/technology is considered in this example (see also [28]).

The multiple objective program includes the following criterion functions.

1. maximize food output (weighted sum of food energy and protein available for human beings after conversion and processing into food commodities; criterion Food_avg);

2. maximize net revenue (criterion Net_rev);

3. minimize production costs (criterion Cost_min);

4. maximize gross value of output (criterion Tot_rev);

5. minimize arable land use (weight of 1 assigned to crops and fuelwood species and 0.1 to grassland; criterion arable);

6. minimize area harvested (criterion Harvest);

7. maximize food output in 'bad' years (weighted sum of food energy and protein available for human comsumption as in 1 above, but evaluated for climatic conditions typical for years with low precipitation levels; criterion Food_min);

8. minimize total erosion (total soil loss over all land units; criterion Eros_tot);

9. maximize self-sufficient ratio (minimum of the individual commodity group self-sufficiency ratios, i.e., target demand over production achieved; criterion SSR_v);

10. minimize erosion at the level of agro-ecological cells (largest soil loss per ha occurring in any used land unit; criterion Eros_max).

The last criterion, termed Eros-max, provides an example of a criterion that retains the spatial detail of the GIS resource database. Other examples of criteria where the spatial content of the information is important could, for instance, evaluate crop diversification or equity of expected farm in- 
comes. We consider it important that the linkage to the GIS is maintained both for generating criterion values as also for mapping scenario results.

The core model is defined in terms of three groups of decision variables which, respectively, determine optimal land use, livestock numbers supported, and optimal allocation of feed supplies to different livestock systems (for details see [28])

(a) the land use shares, i.e., the share $X_{k j}$ of agro-ecological cell $j$ allocated to a cropping, grassland or fuelwood activity $k$;

(b) the number of animal units $L_{s z}$ of livestock system $s$ kept in zone $z$, and

(c) the feed ration $f_{i h t s z}$ of feed item $h$ from crop $i$ allocated to livestock system $s$ in period $t$ in zone $z$. These variables form the columns of the constraint matrix, the core model activity set.

For example, the mathematical formulation of objective 9 (i.e., maximize level of self-sufficiency by commodity group) is

$$
\max _{X_{k j}, L_{s}, f_{i h t s}}=\min _{g} \lambda_{g}
$$

where $\lambda_{s}$ represents the level of self-sufficiency in product group $g$, such as cereals, pulses, meat, milk, etc. (see Table 3 ). Note that production depends primarily on land allocation (decision variables $X_{k j}$ ) and yields. In addition, self-sufficiency is also affected by livestock numbers and feed use (variables $L_{s z}$ and $f_{i h t s z}$, respectively).

The constraints that can be specified in the core model relate to preferred demand baskets, crop specific production targets, risk aversion, economic constraints, land use by individual crop and crop group, crop mix, input use, quality of human diet, environmental conditions, seasonal feed demandsupply balances, feed quality, and distribution of livestock systems (for more details, refer to [28]).

The AEZ core model has been analyzed using the methodology and the DSS described above. The discussion presented here is based on results obtained for a subset of seven criteria (out of ten). These correspond to the items listed above under $1,2,5,7,8,9$, and 10 .

The results of an illustrative analysis for Bungoma district are given in Table 1. The first 7 rows of the table contain the criteria values obtained from solutions where each criterion is optimized separately in successive single-criterion optimization runs (step 1). The diagonal elements of the matrix represent the Utopia values for the 7 criteria (i.e., 1197.2, 1316.6, $96.2,1010.5,1164.9,1337.8,12.2)$. The Nadir values are found by taking the lowest values in the columns of the criteria to be maximized (i.e., Food_avg 
TABLE 1

RESULTS OF ARBDS ANALYSIS FOR BUNGOMA DISTRICT

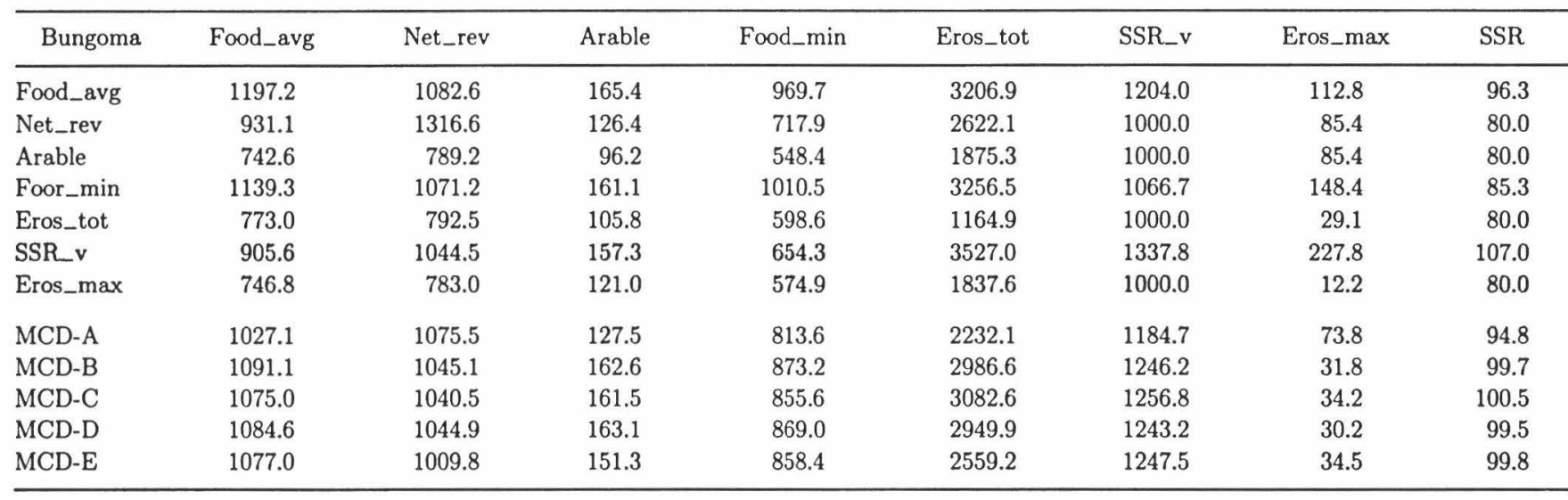


$=742.6 .$, Net_rev $=783.0$, Food_min $=548.4$, SSR_v $=1000.0)$ and the highest values of the columns of the criteria to be minimized (i.e., Arable = 165.4, Eros_tot $=3527.0$, Eros_max $=227.8$ ). The last five rows of Table 1 contain the criteria values resulting from a session of interactive multicriteria analysis involving 5 iterations (step 2).

The multicriteria model analysis is facilitated by a user-friendly Graphical User Interface (GUI). The GUI provides a convenient possibility for easy definition of aspiration and reservation levels for each criterion by either clicking a mouse, or by specifying exact values for these levels by filling fields in dialogs. The values of criteria for different solutions are marked on two dimensional plots for each criterion (see Figure 3 for a screen sample). The plots show the current components achievement functions for each criterion, and in addition, mark values of achievement functions obtained for solutions in previous iterations. All solutions (in the criteria space) are available also in a spreadsheet form and full solutions can be stored for a more detailed analysis. The detailed description of the GUI is presented in [23].

Solution MCD-A represents the compromise solution automatically determined by the system on the basis of the Utopia point and an approximation of the Nadir point. By inspection, we conclude that solution MCD-A allows for too high soil losses in some land units (criterion Eros_max) and, perhaps, puts too much emphasis on minimizing arable land use (criterion Arable). Also, the level of district self-sufficiency in solution MCD-A is less than desired. We use the SAP tool to modify the aspiration and reservation level for these criteria and obtain solution MCD-B. We iteratively adapt the aspiration levels for different criteria and generate a sequence of Paretooptimal solutions MCD-C to MCD-E. Generally, the increase in arable land use required to achieve higher food production and self-sufficiency ratios leads to higher total erosion; food production, economic return, and food security in terms of guaranteed minimum production in bad years and maximum erosion vary within narrow ranges and seem to stabilize. Table 2 contains the acreages of the various crop commodities involved in the production. Table 3 shows, for aggregated groups of commodities, including livestock products, the respective food supplies and commodity group selfsufficiency ratios.

Given that the solutions produce self-sufficiency rates for all aggregate commodities above the $80 \%$ minimum limit which was established for the scenarios, both the MCD-C and MCD-D solutions appear to be good choices as they represent the relatively 'best' optimal combination of values of the decision variables. Since each of the solutions can be stored on a file, a detailed analysis of the resulting cropping patterns and spatial characteristics through inspection and mapping is easily possible. 


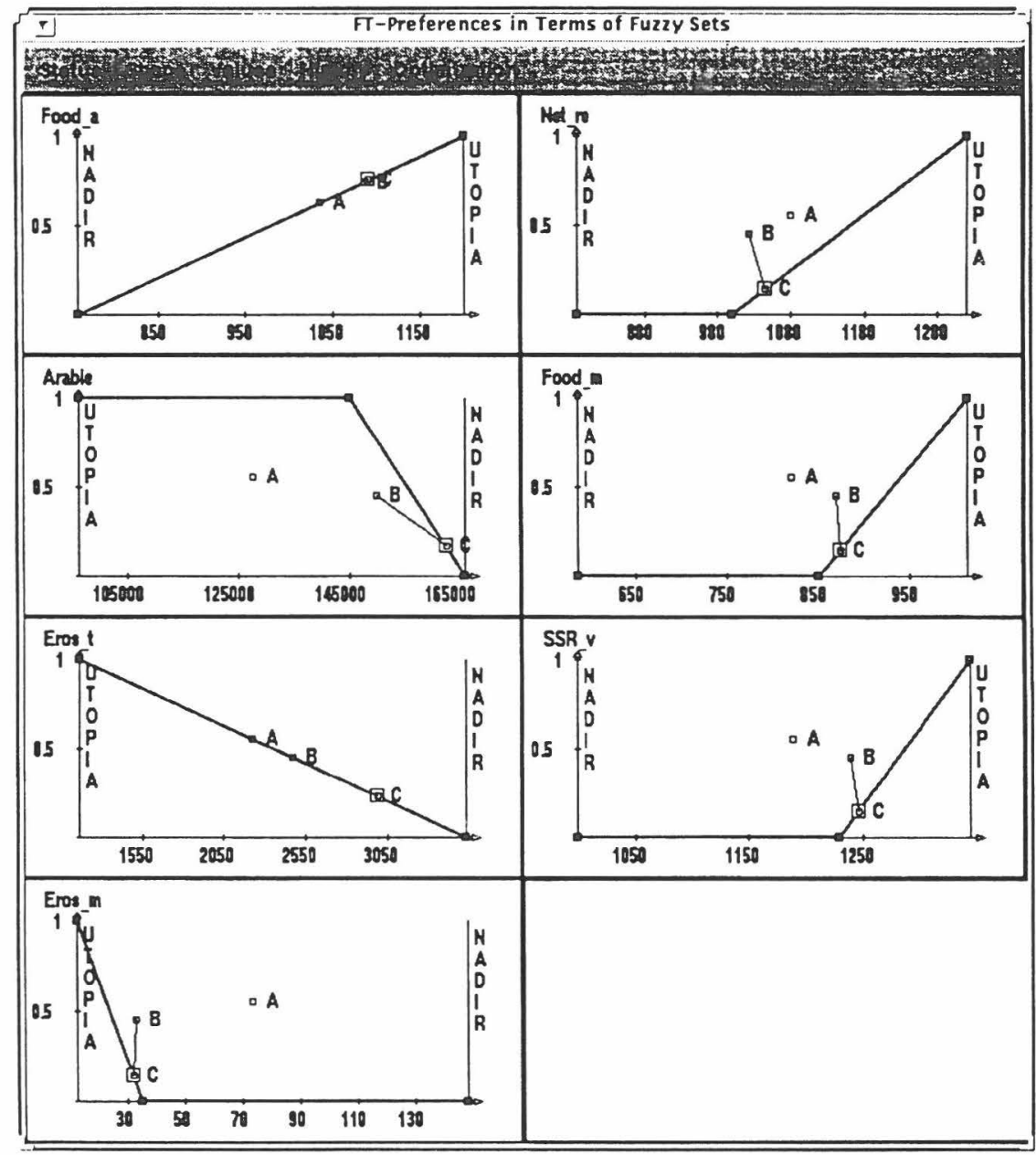

FIG. 3. Sample screen display from SAP-tool [23].

\section{CONCLUSION}

As the above example illustrates, linking multicriteria methods of optimization with GIS land resources databases provides a powerful DSS tool in land use decision-making support. 'Hard' constraints and the sequential analysis of a set of single-criterion solutions, as is necessary in singlecriterion optimization, are replaced by interactive specification of the decision makers' preferences. Moreover, the simplicity and flexibility of the 
TABLE 2

TOTAL HARVESTED AREAS (HA) BY CROP COMMODITY

\begin{tabular}{lrrrrr}
\hline Commodity & MCD-A & MCD-B & MCD-C & MCD-D & MCD-E \\
\hline Barley & 20043 & 18489 & 19026 & 17737 & 18683 \\
Maize & 73497 & 88369 & 89031 & 88124 & 89017 \\
Oats & 0 & 0 & 0 & 0 & 0 \\
Rice & 3623 & 6306 & 6314 & 629.4 & 6040 \\
Sorghum & 2766 & 3776 & 3776 & 3776 & 3776 \\
Wheat & 0 & 59 & 163 & 136 & 64 \\
Beans & 32732 & 38113 & 37877 & 38515 & 37291 \\
Pigcon pea & 1876 & 1409 & 1552 & 1314 & 1566 \\
Cassava & 3527 & 5410 & 5291 & 5270 & 5319 \\
Swcet potato & 0 & 1847 & 2141 & 2151 & 2127 \\
Whitc potato & 627 & 1823 & 2117 & 1776 & 1236 \\
Banana & 7774 & 10090 & 10204 & 10042 & 9987 \\
Sugarcane & 5831 & 17673 & 15833 & 18345 & 10522 \\
Total & 152296 & 193364 & 193327 & 193481 & 185629 \\
\hline
\end{tabular}

approach help the user, during the process of decision-making, to better understand the decision situation. the ARBDS approach is interactive and fast, so that the development of some dozen solutions does not require more than perhaps a few hours for an experienced user with a good understanding of the problem. The user does not need to be a person experienced in sensitivity analysis and scenario generation techniques which are necessary for the analysis based on the single-criterion approach. However, the detailed evaluation of a large number of solutions obtained in ARBDS can be more problematic and much more time consuming then the evaluation of a much smaller number of solutions typically analyzed by single-criterion optimization. On the other hand, the analysis of a larger number of solutions corresponding to different areas of the Pareto-efficient set provides a more complete understanding of the problem. Solutions which are close to each other, as obtained in the Bungoma case, can appear confusing at first to the decision maker. The SAP tool provides an option for analyzing the history of solutions which eases the problem of selecting of solutions. However, this part of the interaction could benefit from further improvements. Many users also have difficulty evaluating more than three criteria visually and quickly. Special techniques are provided by SAP to facilitate an evaluation. This can be done by sequential selection of groups of criteria that are investigated more closely while the remaining criteria are either inactive (i.e., they do not enter the function of (1)) or their values are stabilized around a desired (as sclected for each criterion by the user) target value. 
TABLE 3

FOOD AND FUELWOOD SUPPLIES (TON) AND SELF-SUFFICIENCY RATIOS BY COMMODITY GROUP

\begin{tabular}{|c|c|c|c|c|c|c|c|c|c|c|}
\hline \multirow[t]{2}{*}{ Commodity } & \multicolumn{2}{|c|}{ MCD-A } & \multicolumn{2}{|c|}{ MCD-B } & \multicolumn{2}{|c|}{ MCD-C } & \multicolumn{2}{|c|}{ MCD-D } & \multicolumn{2}{|c|}{ MCD-E } \\
\hline & Supply & $\%$ SSR & Supply & \%SSR & Supply & \%SSR & Supply & $\% \mathrm{SSR}$ & Supply & $\% \mathrm{SSR}$ \\
\hline Cereals & 124871 & 95 & 131345 & 100 & 132458 & 101 & 131031 & 100 & 131487 & 100 \\
\hline Pulses & 12308 & 95 & 12947 & 100 & 13057 & 101 & 12916 & 100 & 12961 & 100 \\
\hline Roots & 46598 & 95 & 47996 & 100 & 48404 & 101 & 47882 & 100 & 48035 & 100 \\
\hline Sugar & 16061 & 95 & 40311 & 238 & 35920 & 212 & 41756 & 246 & 24328 & 144 \\
\hline Bananas* & 43646 & 47 & 45910 & 50 & 46300 & 50 & 45801 & 50 & 45960 & 50 \\
\hline Fuelwood & 43646 & 95 & 45910 & 100 & 46300 & 101 & 45800 & 100 & 45959 & 100 \\
\hline Meat & 10126 & 95 & 10651 & 100 & 10742 & 101 & 10626 & 100 & 10663 & 100 \\
\hline Milk & 109912 & 157 & 69691 & 100 & 70284 & 101 & 69525 & 100 & 69767 & 100 \\
\hline Eggs & 873 & 95 & 918 & 100 & 926 & 101 & 916 & 100 & 919 & 100 \\
\hline
\end{tabular}

*Since banana represents the only fruit crop in the AEZ assessment contributing to this group commodity, the self-sufficiency requirement was relaxed. 
The ARBDS method can also be used for a more detailed model analysis in two ways that have not been applied so far in the case study reported in this paper. The first one is called soft simulation. This is an extension of the traditional simulation allowing to combine multicriteria analysis with (soft) setting of values of selected variables. Secondly, ARBDS allows for treatment of a group of constraints as co-called soft constraints, i.e., constraints that can be violated up to a certain (interactively controlled by the user) bound. Both techniques are discussed in more detail in [7].

To avoid a possible misleading conclusion, namely, that the usage of this DSS package may replace a real decision maker, it should be stressed that the system is designed to help a decision maker to concentrate on real decision making while the program takes care of the cumbersome computations involved in the analysis of scenarios and provides information that serves the analysis of the consequences of different options and alternatives. The user needs to define the various scenarios of interest, changing his/her preferences and priorities when learning interactively about the consequences of possible decisions. Röling [29] has explored the limitation of focusing exclusively on building scenarios on the basis of interactive MCDA, without paying attention to human decision-making in developing and applying those scenarios.

There are a number of constraints to overcome for the successful application of such DSS systems in land use decisions in developing countries. In many of these countries, lack of data and poor data quality remain serious drawbacks to the application of computer-based systems of land resources management. Lack of trained personnel to apply the systems in solving practical problems is another constraint, which often causes the available systems to be underutilized and sometimes not to be used at all. In terms of computer technology, there is the need to adapt the ARBDS software, which currently requires a powerful workstation to run, to the type of $\mathrm{PC}$ platforms generally in use in developing countries.

\section{REFERENCES}

1 R. O. Blake, D. E. Bell, J. T. Mathews, R. S. McNamara, and M. P. McPherson, Feeding 10 Billion People in 2050: The key role of the CGIAR's, and IARC's. A report by the action group on food security, World Watch Institute, Washington, D.C., 1994.

2 R. Brinkman, Recent developments in land use planning, with special reference to FAO. In The Future of the Land: Mobilizing and Integrating Knowledge for Land Use Options. (L. O. Fresco, L. Stroosnijders, J. Bouma, and H. van Keulen, Eds.) John Wiley \& Sons Ltd. 1994.

3 J. Antoine, G. Fischer, and M. Makowski, Multiple criteria analysis in optimizing land use for sustainable agricultural development planning. In First Interma- 
tional Conference on Multiple Objective Decision Support Systems for Land, Water and Environmental Management: Concepts, Approaches and Applications. (draft proceedings) Honolulu, Hawaii, 1995.

4 FAO. Report on the Agro-ecological Zones Project (1978-1981), Vol. 1: Methodology and Results for Africa. World Soil Resources Report 48/1. Rome, 1981.

5 FAO, A framework for land evaluation, Soils Bulletin 32, Rome (1976).

6 W. G. Sombroek and J. Antoine, The use of geographic information systems (GIS) in land resources appraisal, FAO Outlook on Agriculture 23(4):249-255 (1994).

7 M. Makowski, Methodology and a modular tool for multiple criteria analysis of LP models, Working Paper WP-94-102, International Institute for Applied Systems Analysis, Laxenburg, Austria, 1994b.

8 H. Nakayama, Aspiration level approach to interactive multi-objective programming and its applications. Working Paper WP-94-112, International Institute for Applied Systems Analysis, Laxenburg, Austria, 1994.

9 M. Makowski, LP-DIT, Data Interchange Tool for Linear Programming Problems, (Version 1.20). Working Paper WP-94-36, International Institute for Applied Systems Analysis, Laxenburg, Austria, 1994a.

10 T. Stewart, A critical survey on the status of multiple criteria decision making theory and practice, OMEGA, International Journal of Management Science 20(5/6):569-586 (1992).

11 P. Haettenschwiler, Decision Support Systems Applied to Swiss Federal Security Policy and Food Supply, (draft). IIASA, DSS Workshop, 1994.

12 K. Mitani and H. Nakayama, Livestock Ration Formulation by an Interactive Multiobjective Programming Technique. IIASA, DSS Workshop, 1994.

13 M. Penttinen, Forest Owner's Decision Support Systems-A Management Solution for Nonindustrial Private Forest Owners. IIASA, DSS Workshop, 1994.

14 R. Janssen, Multiobjective Decision Support for Environmental Management, Kluwer Academic Publishers, P. O. Box 17, 3300 AA Dordrecht, The Netherlands, 1992.

15 Y. Haimes and W. Hall, Multiobjectives in water resource systems analysis: the surrogate trade-off method, Water Resources Research 10:615-624 (1974).

16 M. Makowski, L. Somlyódy, and D. Watkins, Multiple criteria analysis for water quality management in the nitra basin, Water Resources Bulletin (to appear in August 1996).

17 P. Korhonen and J. Wallenius, Observations regarding choice behaviour in interactive multiple criteria decision-making environments: An experimental investigation. In Methodology and Software for Interactive Decision Support. Lecture Notes in Economics and Mathematical Systems. (A. Lewandowski and I. Stanchev, Eds.). Vol. 337, Springer Verlag, Berlin, New York, 1989.

18 P. Korhonen and J. Wallenius, Multiple objective linear programming decision support, Decision Support Systems Joumal 6:243-251 (1990).

19 L. Gardiner and R. Steuer, Unified interactive multiple objective programming, European Journal of Operational Research, 74:391-406, 1994.

20 J. March and H. Simon. Organizations, J. Wiley \& Sons, New York, 1958. 
21 A. Wierzbicki, A mathematical basis for satisficing decision making, Mathematical Modelling 13:5-29 (1982).

22 A Lewandowski and A. Wierzbicki (Eds.) Aspiration Based Decision Support Systems: Theory, Software and Applications. Lecture Notes in Economics and Mathematical Systems, Vol. 331, Springer Verlag, Berlin, New York, 1989.

23 J. Granat and M. Makowski. SAP-Modular Tool for Specification and Analysis of User Preferences in Multi-Criteria Model Analysis. Working Paper WP-95-73, International Institute for Applied Systems Analysis, Laxenburg, Austria, 1995.

24 H. Isermann and R. E. Steuer, Computational experience concerning payoff tables and minimum criterion values over the efficient set, European J. Oper. Res. 33:91-97 (1987).

25 J. Gondzio and M. Makowski, HOPDM, Modular Solver for LP Problems. User's Guide to Version 2.12. Working Paper, WP-95-50. International Institute for Applied Systems Analysis, Laxenburg, Austria, 1995.

26 A. Wierzbicki, Multi-objective modeling and simulation for decision support. Working Paper WP-92-80, International Institute for Applied Systems Analysis, Laxenburg, Austria, 1992.

27 FAO/IIASA, Agro-ecological assessments for national planning, The example of Kenya. Soils Bulletin 67, Rome (1993).

28 FAO/IIASA. Agro-Ecological Land Resources Assessment for Agricultural Development Planning. A Case Study of Kenya. Making Land Use Choices for District Planning. World Soil Resources Report 71/9. (G. W. Fischer and J. Antoine, authors). Rome, 1994.

29 N. Röling, Platforms for decision-making about ecosystems. In The Future of the Land: Mobilizing and Integrating Knowledge for Land Use Options, (L. O. Fresco, L. Stroosnijders, J. Bouma and H. van Keulen, Eds.). John Wiley \& Sons Ltd., 1994. 


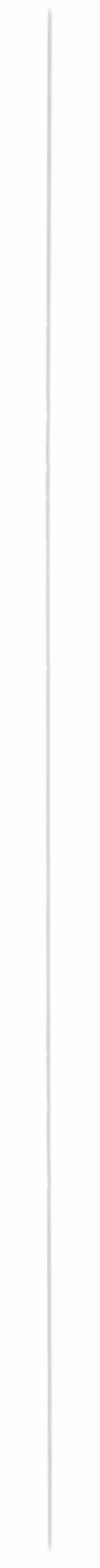

